\title{
Circadian-Dependent and Sex-Dependent Increases in Intravenous Cocaine Self-Administration in Npas2 Mutant Mice
}

\author{
${ }^{\circledR}$ Lauren M. DePoy, ${ }^{1,2}$ DDarius D. Becker-Krail, ${ }^{1,2}$ Wei Zong, ${ }^{3}$ Kaitlyn Petersen, ${ }^{1,2}$ Neha M. Shah, ${ }^{1}$ \\ Jessica H. Brandon, ${ }^{1}$ Alyssa M. Miguelino, ${ }^{1}$ George C. Tseng, ${ }^{3}{ }^{\circledR}$ Ryan W. Logan, ${ }^{1,2,4}$ and \\ ${ }^{-}$Colleen A. McClung ${ }^{1,2,4}$ \\ ${ }^{1}$ Department of Psychiatry, Translational Neuroscience Program, University of Pittsburgh School of Medicine, Pittsburgh, Pennsylvania 15219, \\ ${ }^{2}$ Center for Neuroscience, University of Pittsburgh, Pittsburgh, Pennsylvania 15261, ${ }^{3}$ Department of Biostatistics, University of Pittsburgh, \\ Pittsburgh, Pennsylvania 15261, and ${ }^{4}$ Center for Systems Neurogenetics of Addiction, The Jackson Laboratory, Bar Harbor, Maine 04609
}

Substance use disorder (SUD) is associated with disruptions in circadian rhythms. The circadian transcription factor neuronal PAS domain protein 2 (NPAS2) is enriched in reward-related brain regions and regulates reward, but its role in SU is unclear. To examine the role of NPAS2 in drug taking, we measured intravenous cocaine self-administration (acquisition, dose-response, progressive ratio, extinction, cue-induced reinstatement) in wild-type (WT) and Npas2 mutant mice at different times of day. In the light (inactive) phase, cocaine self-administration, reinforcement, motivation and extinction responding were increased in all Npas 2 mutants. Sex differences emerged during the dark (active) phase with Npas2 mutation increasing self-administration, extinction responding, and reinstatement only in females as well as reinforcement and motivation in males and females. To determine whether circulating hormones are driving these sex differences, we ovariectomized WT and Npas2 mutant females and confirmed that unlike sham controls, ovariectomized mutant mice showed no increase in self-administration. To identify whether striatal brain regions are activated in Npas 2 mutant females, we measured cocaine-induced $\Delta$ FosB expression. Relative to WT, $\Delta$ FosB expression was increased in D1+ neurons in the nucleus accumbens (NAc) core and dorsolateral (DLS) striatum in Npas2 mutant females after dark phase self-administration. We also identified potential target genes that may underlie the behavioral responses to cocaine in Npas2 mutant females. These results suggest NPAS2 regulates reward and activity in specific striatal regions in a sex and time of day (TOD)-specific manner. Striatal activation could be augmented by circulating sex hormones, leading to an increased effect of Npas2 mutation in females.

Key words: circadian; cocaine; Npas2; self-administration; sex-differences; substance use

Significance Statement

Circadian disruptions are a common symptom of substance use disorders (SUDs) and chronic exposure to drugs of abuse alters circadian rhythms, which may contribute to subsequent SU. Diurnal rhythms are commonly found in behavioral responses to drugs of abuse with drug sensitivity and motivation peaking during the dark (active) phase in nocturnal rodents. Emerging evidence links disrupted circadian genes to SU vulnerability and drug-induced alterations to these genes may augment drug-seeking. The circadian transcription factor neuronal PAS domain protein 2 (NPAS2) is enriched in reward-related brain regions and regulates reward, but its role in SU is unclear. To examine the role of NPAS2 in drug taking, we measured intravenous cocaine self-administration in wild-type (WT) and Npas2 mutant mice at different times of day.

Received July 15, 2020; revised Nov. 13, 2020; accepted Nov. 18, 2020.

Author contributions: L.M.D., R.W.L., and C.A.M. designed research; L.M.D., D.D.B.-K., K.P., N.M.S., J.H.B., and A.M.M. performed research; L.M.D., W.Z., and G.C.T. analyzed data; L.M.D. wrote the paper.

This work was supported by NIH Grants DA039865, DA041872, DA039841, and DA042886 (to C.A.M.) and DA046117 (to L.M.D.). We thank Mariah Hildebrand and Laura Holesh for animal care and genotyping. We also thank Dr. Steven McKnight and Dr. David Weaver for providing the Npas2 mutant mice. This project used the University of Pittsburgh Health Sciences Sequencing Core at University of Pittsburgh Medical Center Children's Hospital of Pittsburgh (RNA sequencing). Cocaine was provided by National Institute on Drug Abuse via the National Institutes of Health $(\mathrm{NIH})$ drug distribution center.

The authors declare no competing financial interests.

Correspondence should be addressed to Colleen A. McClung at mcclungca@upmc.edu.

https://doi.org/10.1523/JNEUROSCI.1830-20.2020

Copyright $\odot 2021$ the authors

\section{Introduction}

Circadian disruptions are a common symptom of many psychiatric disorders (Kowatch et al., 1992; Morgan and Malison, 2007; Matuskey et al., 2011), including substance use disorder (SUD; Spanagel et al., 2005; McClung, 2007; Logan et al., 2014; DePoy et al., 2017a). Diurnal rhythms in the behavioral responses to drugs of abuse are common with drug sensitivity and drug use peaking during the active compared to inactive phase, or dark and light, respectively, in nocturnal rodents (Baird and Gauvin, 2000; Abarca et al., 2002; Roberts et al., 2002; Sleipness et al., 
2005). Chronic exposure to drugs of abuse alters circadian rhythms, which may contribute to subsequent SU (Roberts et al., 2002; Logan et al., 2014; DePoy et al., 2017a). Emerging evidence from rodents and humans links disrupted circadian genes to SU vulnerability (Dong et al., 2011; Forbes et al., 2012; Ozburn et al., 2012, 2013; Blomeyer et al., 2013; Gamsby et al., 2013; Bi et al., 2014; Baranger et al., 2016) and druginduced alterations to these genes may augment drug-seeking.

Almost every cell in the brain and body expresses a molecular clock, comprised of several interlocking transcriptional-translational feedback loops (Reppert and Weaver, 2002; Ko and Takahashi, 2006; Takahashi, 2017). The molecular clock is regulated by circadian locomotor output cycles kaput (CLOCK) or its homolog, neuronal PAS domain protein 2 (NPAS2), which dimerize with brain and muscle ARNT-like 1 (BMAL1) to control transcription of many genes. After translation, these proteins enter the nucleus and inhibit the transcriptional activity of (CLOCK/NPAS2)/BMAL1, closing the negative feedback loop (Ko and Takahashi, 2006). Our laboratory has previously demonstrated that mutations in Clock lead to increased cocaine and alcohol intake in mice (McClung et al., 2005; Ozburn et al., 2012, 2013) and a loss of diurnal rhythmicity in cocaine self-administration (Roberts et al., 2002). We have also shown that while Clock mutation increases cocaine preference, Npas2 mutation attenuates preference (Ozburn et al., 2015). NPAS2 is similar to CLOCK in structure and function, yet relative to CLOCK, NPAS2 expression and promotor binding is highly rhythmic in the striatum (Garcia et al., 2000; Ozburn et al., 2015), including the nucleus accumbens (NAc), a major neural substrate of reward (Wise and Rompre, 1989). In fact, in the NAc rhythms in Npas 2 are more highly affected by cocaine than Clock (Falcon et al., 2013) and Npas2 knock-down increases glutamatergic transmission onto dopamine Drd1-expressing neurons (Parekh et al., 2019). Together, these findings suggest NPAS2 might play a uniquely important role in the regulation of reward within the striatum.

This study aimed to determine whether NPAS2 regulates intravenous cocaine self-administration, a translational model of drug taking, the reinforcing and motivational properties of drugs and relapse-like behavior. We investigated whether Npas 2 mutation modulates the diurnal rhythm in drug taking by measuring self-administration during both the light and dark phase. We also examined whether Npas 2 mutation differentially impacts male and female mice since sex differences are prominent in circadian rhythms (Hatcher et al., 2020) and SUD (Becker and $\mathrm{Hu}$, 2008). We find that NPAS2 regulates cocaine self-administration differentially across sex and time of day (TOD). Ovarian hormones and cocaine-induced expression of striatal $\Delta$ FosB are associated with increased self-administration in Npas 2 mutant females during the dark phase. Furthermore, we identify potential target genes that might underlie the behavioral responses to cocaine in Npas 2 mutant females.

\section{Materials and Methods}

\section{Subjects}

Male and female Npas2 mutant mice or wild-type (WT) littermates, maintained on a C57BL/6J background, were used. These mice were originally described by Garcia et al. (2000). This mutation removes the bHLH domain of NPAS2, leaving the majority of the protein intact, but incapable of binding to BMAL1 (Garcia et al., 2000). Adult mice were maintained on a $12 / 12 \mathrm{~h} \mathrm{light/dark} \mathrm{cycle} \mathrm{with} \mathrm{lights} \mathrm{on} \mathrm{[zeitgeber} \mathrm{time}$ (ZT)0] at 7 A.M. or 7 P.M. Behavioral testing occurred during the light phase from ZT2-ZT7, unless specifically indicated as a dark phase experiment (ZT14-ZT19). Food and water were provided ad libitum unless otherwise indicated. Procedures were approved by the University of Pittsburgh Institutional Animal Care and Use Committee.

\section{Drug}

Cocaine hydrochloride was provided by the National Institute on Drug Abuse. Animals were injected with 2.5, 5, or $15 \mathrm{mg} / \mathrm{kg}$ (i.p.; volume 10 $\mathrm{ml} / \mathrm{kg}$ ) in conditioned place preference (CPP) and locomotor sensitization and $0-1 \mathrm{mg} / \mathrm{kg} /$ infusion for cocaine self-administration.

\section{Surgery}

Jugular catheterization

Mice were anesthetized with a $100 \mathrm{mg} / \mathrm{kg}$ ketamine $/ 1 \mathrm{mg} / \mathrm{kg}$ xylazine mixture. Surgery was performed under white light, during the second half of the inactive phase, regardless of light housing conditions for the mice. As previously described (Ozburn et al., 2012; DePoy et al., 2017b), the dorsal and ventral sides were shaved and disinfected. The right jugular vein was exposed by blunt dissection and a sterile polyurethane catheter was placed and secured to the vein. The catheter is exteriorized posterior to the scapulae via a dacron mesh mount (Instech). The dorsal and ventral wounds were sutured and mice were pair housed for the duration, unless fighting or uneven sample sizes necessitated single housing. Mice recover for 6-7 days (d) before intravenous self-administration training begins. Catheters were maintained by infusing catheters daily with $0.05 \mathrm{ml}$ gentamicin $(0.33 \mathrm{mg} / \mathrm{ml})$ and heparinized saline (30 USP/ $\mathrm{ml})$ containing baytril $(0.5 \mathrm{mg} / \mathrm{kg})$. Catheter patency was tested approximately once per week using $0.05 \mathrm{ml}$ brevital $(3 \mathrm{mg} / \mathrm{ml})$, mice that failed to lose muscle tone were excluded.

\section{Ovariectomy (OVX)}

OVX was performed as previously described (Heger et al., 2003). Female mice of at least 10 weeks of age were anesthetized with isoflurane. The ventral side was shaved and disinfected. The ovaries were located and either left intact or ligated and removed in sham and ovariectomized groups, respectively. The abdominal wall was secured with absorbable sutures and the skin stapled. Mice were allowed to recover for at least $10 \mathrm{~d}$ before food training began. Because of previous isoflurane treatment mice were also anesthetized with isoflurane during the jugular catheterization. Following surgery, mice were moved from a $12 / 12 \mathrm{~h}$ light/dark cycle to a reverse light cycle (7 P.M. on) to acclimate before behavioral testing. Mice were allowed to recover for at least $10 \mathrm{~d}$, ensuring reduced levels of circulating sex hormones before food training began. Hormones should be entirely ablated before cocaine selfadministration.

\section{Behavioral testing}

$C P P$

As previously described (Ozburn et al., 2015), female mice eight weeks and older were first habituated to a testing room for $30 \mathrm{~min}$. On day 1, a preconditioning test was conducted, wherein mice were placed in the center of a three-chamber box. The outer two chambers were distinct with visual and tactile differences. Time in each chamber was recorded over the 20 -min session and any mice spending $\geq 50 \%$ (600 s) in one zone were excluded. On the subsequent $4 \mathrm{~d}$, mice were injected with either saline or cocaine and restricted to one side of the chamber. Saline was injected on $\mathrm{d} 2$ and 4 , and cocaine was injected on $\mathrm{d} 3$ and 5 (2.5 or $5 \mathrm{mg} / \mathrm{kg}, 10 \mathrm{ml} / \mathrm{kg}$, NIDA drug consortium). Here, a biased design was used, since $\geq 50 \%$ of mice showed a chamber bias during the pre-test, wherein the preferred chamber ( $>10 \%$ preference) was paired with saline or chambers were assigned pseudo-randomly if no side preference was found.

\section{Locomotor sensitization}

One cohort of animals were used to examine locomotor sensitization at least one month following CPP for cocaine. All testing was done in clear Plexiglas test chambers (Kinder Scientific Smart Cage Rack System; field dimensions: $9.5^{\prime \prime} \times 18.0$ ") equipped with infrared photobeams measuring horizontal locomotor activity. Before beginning each session, mice were allowed to acclimate to the test room for 1 hour (h). Briefly, the 
protocol began with $1 \mathrm{~d}$ of habituation to the test chamber and $2 \mathrm{~d}$ of $10 \mathrm{ml} / \mathrm{kg}$ saline injections (intraperitoneal). Mice were then given five consecutive $\mathrm{d}$ of $15 \mathrm{mg} / \mathrm{kg}$ cocaine injections (intraperitoneal). Following a 7-d withdrawal period, mice were given two consecutive challenge days of cocaine at the same dose. For all sessions, 60 minutes $(\mathrm{min})$ of locomotor activity was measured as distance traveled $(\mathrm{cm})$, both in total and across 5-min bins. Chambers were cleaned with $70 \%$ ethanol between animals.

\section{Food self-administration}

Mice were restricted to $85 \%$ of their free-feeding weight. Mice were trained to respond for chocolate flavored food pellets $(20 \mathrm{mg}$, grainbased precision pellets, Bio-Serv) in MedAssociates operant conditioning chambers. Responding on one lever was reinforced using a fixed ratio 1 (FR1) schedule. A cue light was illuminated over the active lever for the duration of the experiment. Responses on the inactive lever had no programmed consequences but were recorded. Sessions ended at $60 \mathrm{~min}$ or when the maximum of 30 pellets were acquired. Mice were trained for at least five sessions or until they acquired $\geq 25$ pellets for three consecutive sessions.

Intravenous cocaine self-administration After recovery from jugular catheterization, mice were trained to respond on an FR1 schedule for cocaine $(0.5 \mathrm{mg} / \mathrm{kg} /$ infusion, $30 \mu$ over $1.7 \mathrm{~s}$ ) on the previously inactive lever from food training (Ozburn et al., 2012). Cocaine was delivered through an armored tether connected to a swivel and syringe pump. Mice were tested $6 \mathrm{~d} /$ week with the last day being reserved for patency testing. Drug delivery culminated in extinction of the house light, a compound cue (auditory tone and stimulus light), and a 10-second (s) timeout during which no additional cocaine reinforcers can be delivered. Sessions ended when mice self-administered 60 infusions or at 60 min (first eight sessions) or $120 \mathrm{~min}$ (subsequent sessions, six minimum). Mice were considered to have acquired the cocaine-reinforced response when mice self-administered $\geq 15$ reinforcers across three sessions (with $\geq 2: 1$ active/inactive lever press ratio). Drug intake (infusions), discrimination of the active versus inactive and time to reach criteria were measured.

After acquisition, mice were tested on an FR1 schedule with two consecutive sessions of descending unit doses of cocaine (1.0, 0.5, 0.25, $0.125,0.063$, and $0 \mathrm{mg} / \mathrm{kg}$ ). This dose-response analysis measured the reinforcing properties of cocaine, which will be described throughout as reinforcement.. Next, mice self-administered cocaine at the baseline $0.5 \mathrm{mg} / \mathrm{kg}$ unit dose for $2 \mathrm{~d}$ before progressive ratio testing. In order to measure motivation to take cocaine in the same mice, three counterbalanced unit doses $(1.0,0.5$, and $0.25 \mathrm{mg} / \mathrm{kg})$ were presented for two consecutive sessions under a progressive ratio schedule, wherein each successive infusion requires more lever press responses $(1,2,4,6,9,12$, $16,20 \ldots 240)$. Sessions end after 4 or $1.5 \mathrm{~h}$ without acquiring a reinforcer. This test is used to measure motivation, which will be used to describe changes to the breakpoint ratio, or the last ratio obtained for a dose of cocaine. Mice were again returned to their baseline self-administration dose $(0.5 \mathrm{mg} / \mathrm{kg} /$ infusion $)$ for $2 \mathrm{~d}$ before extinction training. Here, all lever presses had no programmed consequences and mice were trained for $10 \mathrm{~d}$ or until $\leq 30 \%$ peak active responding at $0.5 \mathrm{mg} / \mathrm{kg} /$ infusion was reached. Following extinction, mice were tested for sensitivity to cueinduced reinstatement, a model of relapse where presentations of previously cocaine-associated cues invigorate responding on the previously cocaine-reinforced lever. Mice received one non-contingent cue presentation, followed by cues contingent on responding on the previously active lever.

Mice used for $\Delta$ FosB quantification self-administered cocaine $(0.5 \mathrm{mg} /$ $\mathrm{kg} /$ infusion) for $14 \mathrm{~d}$ as above. Here, in an attempt to normalize cocaine intake between WT and Npas2 mutant mice, infusions were limited to 25, the approximate average number of infusions acquired by WT females during self-administration. After 25 infusions were obtained, the session ended, and mice were removed from the chambers.

\section{Dual RNAscope and immunohistochemistry (IHC)}

RNAscope in situ hybridization (ISH) for Drd1 was followed by IHC for $\Delta$ FosB. The percent of dopamine D1 receptor+ and D1 receptor$(\mathrm{D} 1+, \mathrm{D} 1-)$ neurons expressing $\Delta$ FosB were measured since these populations differentially regulate reward (Lobo et al., 2010; Yawata et al., 2012; Smith et al., 2013). Mice were trained to self-administer cocaine and brains were flash frozen $24 \mathrm{~h}$ after the last self-administration session. Coronal sections $(14 \mu \mathrm{m})$ were cut on a cryostat (Leica) and serial sections between 1.54 and $0.86 \mathrm{~mm}$ from bregma were immediately mounted onto Super Frost Plus slides. Each resulting slide contained 
Females ZT2

A

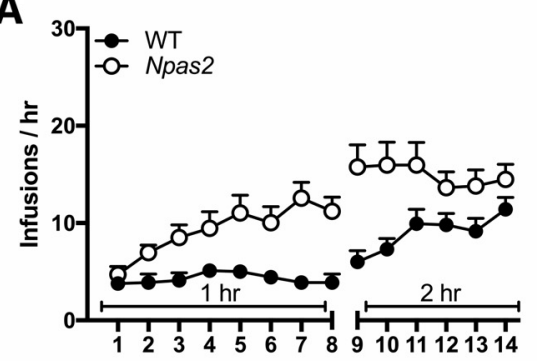

Males
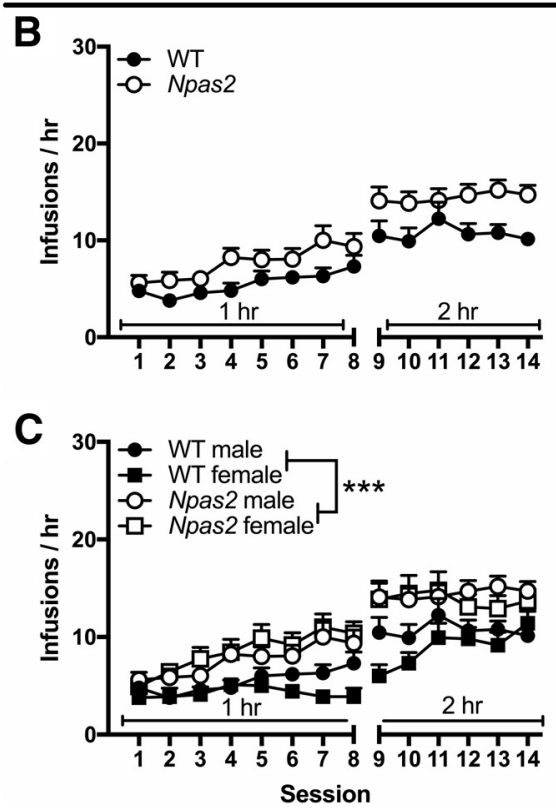
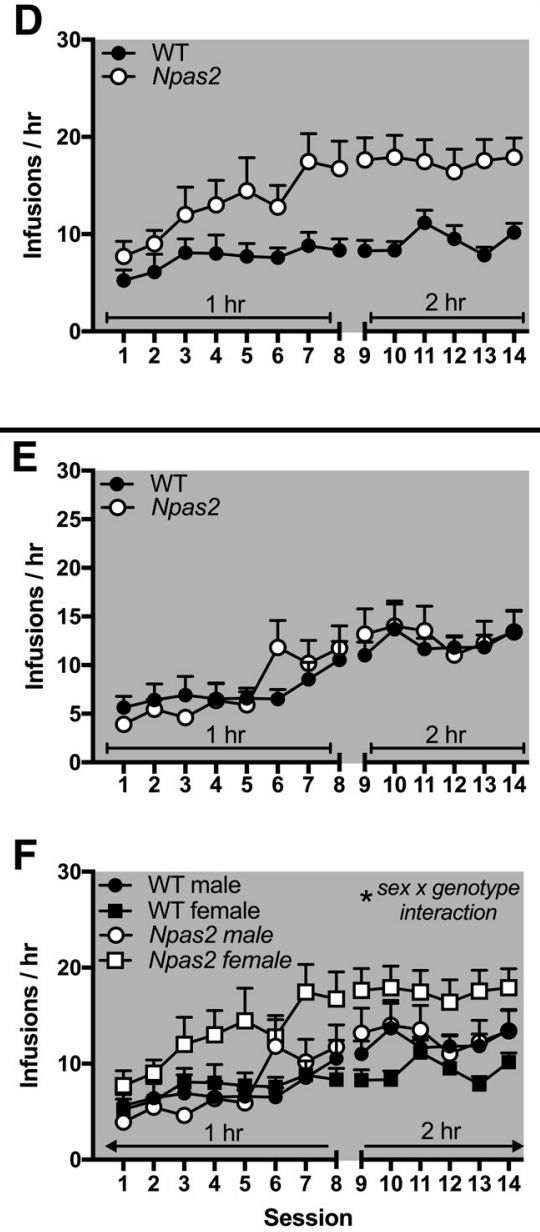

Figure 2. Npas2 mutant mice self-administer more cocaine, particularly females in the dark phase. Npas2 mutant mice were trained to self-administer cocaine $(0.5 \mathrm{mg} / \mathrm{kg} /$ infusion). $\boldsymbol{A}, A \mathrm{At} Z \mathrm{ZT2}$, during the light phase, increased cocaine intake is seen in $(\boldsymbol{A})$ female and $(\boldsymbol{B})$ male Npas2 mutant mice. $\boldsymbol{C}$, Although this effect seems to be particularly pronounced in female mice, overall no sex difference was found and all Npas2 mutant mice self-administered more cocaine than WT mice. $\boldsymbol{D}$, In the dark, or active, phase (ZT14) cocaine intake appears to be elevated in female Npas2 mutant mice compared to WT, $(\boldsymbol{E})$ but not male mutants, $(\boldsymbol{F})$ which is confirmed by a sex by genotype interaction. Mean $+\mathrm{SEM} ; * p<0.05, * * * p<0.001$, $n=10-19$

four sections ranging along the anterior-posterior extent of the striatum. Slides with frozen sections were processed using an RNAscope fluorescent multiplex kit $\times$ (Advanced Cell Diagnostics \#320850). Tissue sections were fixed at $4^{\circ} \mathrm{C}$ in $10 \%$ normal buffered formalin for $30 \mathrm{~min}$ and slides were rinsed three times $1 \times$ PBS then dehydrated in a series of ethanol solutions at room temperature (RT; $50 \%, 70 \%, 100 \%, 100 \%$ ethanol). We then hybridized the tissue sections with a Drd1 probe (Advanced Cell Diagnostics 406491) and incubated slides at $40^{\circ} \mathrm{C}$ for 2 $\mathrm{h}$ in the HybEZ oven. The signal was then amplified through incubation at $40^{\circ} \mathrm{C}$ with sequential amplifiers (AMP1 $30 \mathrm{~min}$, AMP2 $15 \mathrm{~min}$, AMP3 $30 \mathrm{~min}$ ) with AMP4 AltA used to detect Drd1 in green (Alexa Fluor 488). Slides were washed twice in $1 \times$ wash buffer between incubations and then rinsed in PBS before immunohistochemical staining for $\Delta$ FosB $(3 \times 10 \mathrm{~min})$.

Mounted sections were blocked for $1 \mathrm{~h}$ at RT in $10 \%$ normal donkey serum and $0.3 \% 100 \times$ triton. Tissue was then incubated in a rabbit antiFosB primary antibody (1:200, Cell Signaling Technology 2251) in block overnight at $4^{\circ} \mathrm{C}$. After rinsing in PBS, sections were incubated in donkey anti-rabbit Alexa Fluor 555 secondary antibody (1:500, Thermo Fisher Scientific A-31572) in block at RT for $1.5 \mathrm{~h}$, rinsed again, counterstained with DAPI and cover-slipped with prolong gold. Throughout, sections were incubated by filling the hydrophobic barrier with $\sim 150 \mu \mathrm{l}$ of each solution. Although a pan-FosB antibody was used, full-length FosB degrades within 18$24 \mathrm{~h}$ (Perrotti et al., 2008), therefore, all immunoreactivity should reflect $\Delta$ FosB.

\section{Imaging and cell counting}

Immunofluorescence images [DAPI (blue), D1 (488 channel, green), and $\triangle \mathrm{FosB}$ (546 channel, red)] were captured on an Olympus IX83 confocal microscope using a $20 \times$ objective at $2 \times$ magnification. $\sim 300 \times 300-\mu \mathrm{m}$ images were taken from sections along the anterior-posterior extent of the NAc core and shell, and dorsomedial (DMS) and dorsolateral (DLS) striatum. Five to six $2.5-\mu \mathrm{m} z$-stacks were used with an 8$\mu$ s/pixel dwell time and $1024 \times 1024$-pixel size. Consistent laser power, voltage and offset were used between images. Both hemispheres of two to four brain sections/region were imaged. Total D1+ and D1- cells as well as D1+ and D1- $\Delta$ FosB-expressing cells were counted using ImageJ. The percentage of $\mathrm{D} 1+$ and $\mathrm{D} 1-$ $\Delta$ FosB-expressing cells was calculated for all conditions and brain regions. Image capture and quantification were performed by one blinded experimenter.

\section{RNA-sequencing}

Brains were extracted and flash frozen from cocaine naive, adult Npas2 mutant or WT female mice in the dark phase at $\sim$ ZT16, matching time of death after self-administration when $\Delta \mathrm{FosB}$ expression was measured. Bilateral 1$\mathrm{mm}$ punches were taken centered over the NAc, DMS, or DLS. Individual animals were each used as a sample ( $n=4-6$ per condition). Tissue was homogenized and total RNA was isolated using the RNeasy Plus Micro kit (QIAGEN). RNA quantity and quality were assessed using fluorometry (Qubit RNA Broad Range Assay kit and Fluorometer; Invitrogen) and chromatography (Bioanalyzer and RNA 6000 Nano kit; Agilent), respectively. Libraries were prepared using TruSeq mRNA kit for stranded mRNA. Total RNA input was enriched for mRNA and fragments. Random primers initiate first strand and second strand cDNA synthesis. Adenylation of $3^{\prime}$ ends was followed by adapter ligation and library amplification with indexing. High Output, 400 million clustered flowcells (75 cycles) were sequenced with the NextSeq500 platform (Illumina) in 75-bp single read mode. A total of 30 million reads per sample was targeted. Data were filtered for nonexpressed and low-expressed genes. Differential expression (DE) between genotypes, ingenuity pathway analysis (IPA) of enriched differentially expressed genes (DEGs) and rank-rank hypergeometric overlap (RRHO) between brain regions were performed.

\section{Statistical analyses}

GraphPad Prism 7 and IBM SPSS statistics were used. Data are expressed as mean + SEM with $p=0.05$ considered significant and $0.05<p<0.1$ considered trending. Analysis of variance (ANOVAs) were performed with significant interactions followed by Bonferroni post hoc tests corrected for multiple comparisons. Unpaired one-tailed $t$ tests were used to analyze factors such as total infusions (Fig. 7) since we are expecting to replicate and then reverse the increase in self-administration seen in female Npas 2 mutants.

For food and drug self-administration experiments, four-way repeated measure $(\mathrm{RM})$ ANOVAs $(\operatorname{session} \times \operatorname{sex} \times$ genotype $\times$ 
TOD) were used to determine overall effects across all groups tested. However, since light phase and dark phase animals cannot be tested concurrently because of light constraints, as well as the a priori hypothesis that mice would selfadminister more cocaine during the dark phase, each phase was then measured separately. Here, three-way RM ANOVAs were used (session/drug $\times \operatorname{sex} \times$ genotype). These same analyses were performed when lever pressing was analyzed, but five-way and four-way RM ANOVAs were used with the additional factor of lever. Data are also represented for males and females separately to highlight any relevant sex differences, although these ANOVAs were not performed (and statistics are not reported) unless significant three-way interactions were detected. Criteria, total infusions, CPP, and $\triangle \mathrm{FosB}$ were analyzed with twoway ANOVAs (sex $\times$ genotype). Throughout, significant main effects and interactions are described. Values $\geq 2$ SDs from the mean were considered outliers and excluded.

For sequencing, non-expressed genes were first removed and then the 25\% low-expressed genes were filtered out. A total of 14,270 annotated genes remaining after filtering were used as a background data set. $\mathrm{DE}$ analysis comparing WT and mutant mice was conducted by limma-voom in each brain region separately. Genes were considered $\mathrm{DE}$ with a loose $p$ value criterion of $p<0.05$ without multiple comparison correction. We used RRHO as a threshold-free method to evaluate the overlap of DE patterns across pairs of brain regions (Cahill et al., 2018). RRHO identifies overlap between two ranked lists of differential gene expression. The genes are ranked by the $-\log 10$ ( $p$ value) multiplied by the effect size direction. To rank the overlapping genes from RRHO by their DE significance, we performed adaptively-weighted Fisher's (AW-Fisher; Li and Tseng, 2011; Huo et al., 2020) analysis to combine the DE results for DLS and NAc. This provides a meta-analyzed $p$ value for each gene with increased statistical power and generates weight indicators to reflect the consistency of DE signals in the two regions [i.e., $(1,1) \mathrm{DE}$ in both regions, $(1,0)$ DE in DLS but not NAc, and $(0,1)$ DE in NAc but not DLS]. Overlapping genes between DLS and NAc were then ranked by their AW-Fisher meta-analyzed $p$ values. Fisher's exact test was used to test enrichment significance of DEGs in gene sets downloaded from http://ge-lab.org/gskb/. Pathways whose size are smaller than three or $>500$ were not considered.

\section{Results}

Npas 2 mutant mice have altered behavioral responses to cocaine

To expand on evidence that NPAS2 regulates the behavioral effects of cocaine, we examined the role of NPAS2 in a translational model of drug taking, intravenous cocaine self-administration. We measured behavior in male and female Npas 2 mutant mice during the light or dark phase, since NPAS2 regulates circadian rhythms (Ko and Takahashi, 2006; Takahashi, 2017).

Animals were first trained to respond for food and discriminate between the two levers over time [day $\times$ lever interactions: light $\left(F_{(4,440)}=435.04, p<0.0001\right)$, dark $\left.\left(F_{(4,252)}=114,45, p<0.0001\right)\right]$. A four-way ANOVA revealed that response rates varied by genotype and TOD (session $\times$ genotype $\times$ TOD interaction: $F_{(4,173)}=$ $4.19, p=0.002$ ) and throughout, light and dark phase behavior were analyzed individually to identify TOD-specific effects. During the light phase, response rates tended to vary by genotype and sex $\left(\right.$ sex $\times$ genotype interaction: $F_{(1,110)}=2.92, p=0.09$; Fig. $\left.1 A-C\right)$. On the other hand, only genotype differences were found during the
ZT2

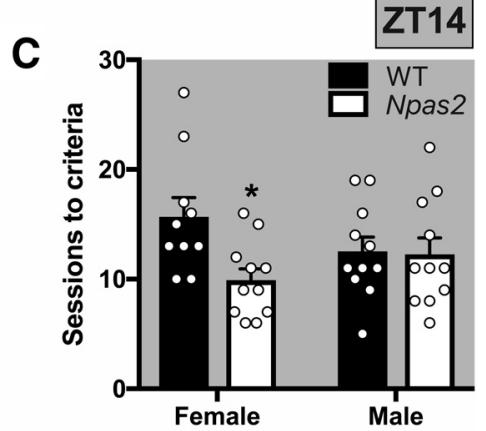

D

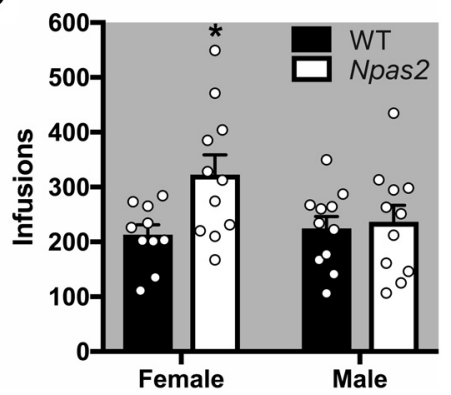

Figure 3. Npas2 mutants have a greater propensity to self-administer cocaine. $\boldsymbol{A}$, An Npas2 mutation increased the propensity to self-administer cocaine, decreasing the days required to reach acquisition criteria, during the light these effects were selective to females. Mean + SEM; individual data points are shown, $* p<0.05$,

dark phase (main effect of genotype: $F_{(1,63)}=4.12, p=0.046$; Fig. $1 D-F)$ where mutants responded more on an active lever for food compared to WT mice.

After recovery from jugular catheterization, mice were trained to self-administer cocaine. As expected, self-administration was higher during the dark than light phase in all mice, as shown by a main effect of TOD $\left(F_{(1,95)}=10.94, p<0.001\right)$. Overall, Npas 2 mutation differentially affects males and females (four-way ANOVA; sex $\times$ genotype: $\left.F_{(1,95)}=4.18, p=0.044\right)$. Subsequent three-way ANOVAs were used to investigate the effects of Npas 2 mutation across TOD. During the light phase, male and female (Fig. 2A,B) Npas2 mutant mice self-administered more cocaine than WT mice (main effect of genotype: $F_{(1,56)}=15.98, p<$ 0.001 ; Fig. $2 C$ ). On the other hand, cocaine intake varied by sex and genotype in the dark phase (sex $\times$ genotype interaction: $F_{(1,63)}=4.65, p=0.037$; Fig. $\left.2 D-F\right)$. To further investigate these effects, we quantified sessions required to reach criteria and total drug intake (infusions). While all Npas 2 mutant mice acquired self-administration faster and took more infusions than WT mice in the light phase [main effect of genotype: criteria $\left(F_{(1,53)}=\right.$ $4.74, p=0.034)$, infusion $\left(F_{(1,56)}=16.1, p=0.0002\right)$; Fig. $\left.3 A, B\right]$, sex differences emerged during the dark phase where only females mutants had a higher propensity to self-administer cocaine compared to WT females [sex $\times$ genotype interaction: criteria $\left(F_{(1,39)}=3.92, p=0.055\right)$, infusion $\left(F_{(1,39)}=3.12, p=0.085\right)$; Fig. $3 C, D]$. This finding demonstrates that female Npas 2 mutants indeed have increased self-administration during the dark phase, while males are unaffected.

In addition to analyzing cocaine intake directly using infusions, we also analyzed active and inactive lever pressing to determine whether Npas 2 mutant mice are taking more cocaine because of overall hyperactivity, which would lead to increases in both active and inactive lever pressing. A five-way ANOVA revealed that all mice, both WT and mutant, discriminate between the active and 
Females ZT2
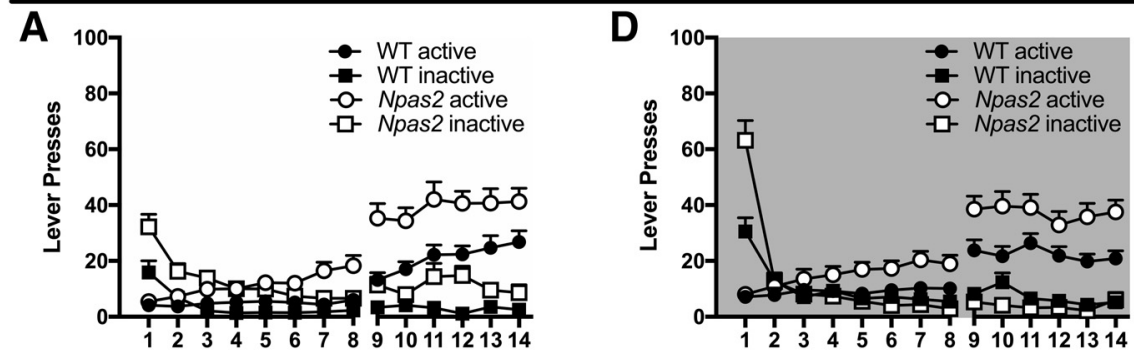

Males
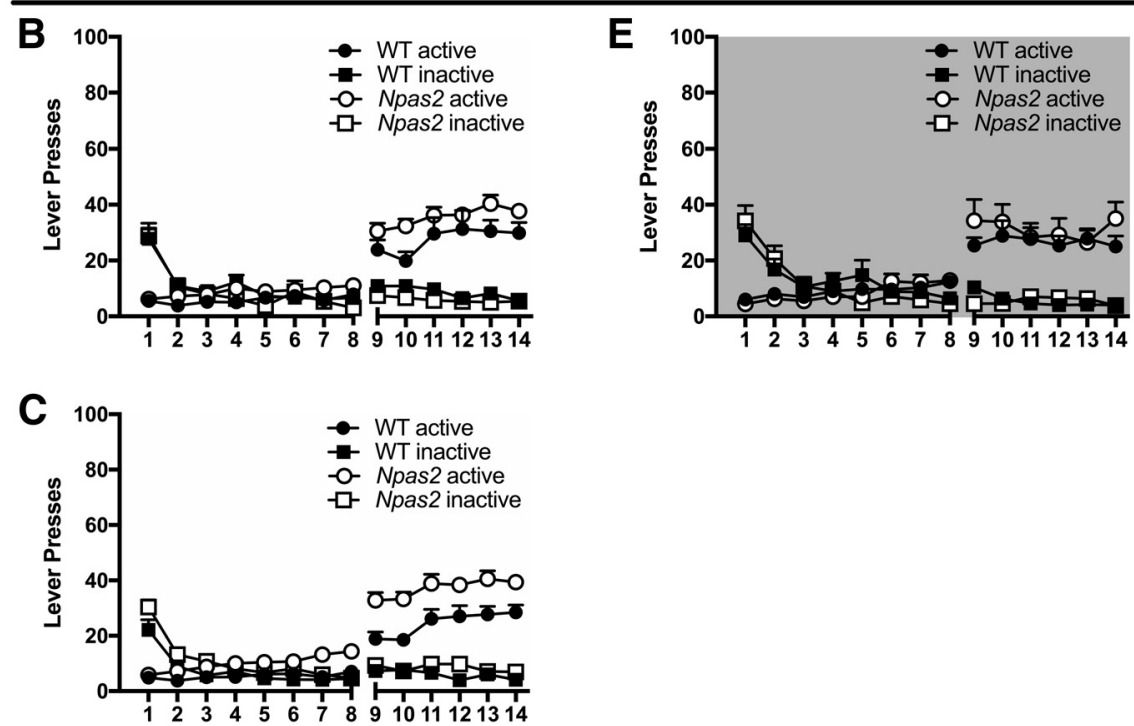

Figure 4. Npas2 mutant mice respond more on an active lever for cocaine, particularly females in the dark phase. $\boldsymbol{A}$, At ZT2, during the light phase, increased active lever pressing for cocaine is seen in $(\boldsymbol{A})$ female and $(\boldsymbol{B})$ male Npas2 mutant mice. $\boldsymbol{C}$, Although this effect seems to be greater in female mice, no sex difference was found. All Npas2 mutant mice pressed the active lever more than WT mice (no post hocs shown), while only a trending increase in inactive lever pressing was found. Both WT and Npas2 mutants press the active lever more than the inactive lever. $\boldsymbol{D}$, In the dark, or active, phase (ZT14), active lever pressing is elevated in female Npas2 mutant mice (no post hocs shown), $(\boldsymbol{E})$ but not male mutants. Both WT and Npas2 mutants press the active more than the inactive lever. Mean + SEM; $n=10-19$.

inactive lever and respond differentially across TOD (session $\times$ lever $\times$ sex $\times$ TOD interaction: $\left.F_{(13,1196)}=1.99, p=0.019\right)$. Subsequently, four-way ANOVAs were used to investigate the effects of Npas2 mutation in the light and dark phase separately. During the light phase, active versus inactive lever pressing varied by genotype (day $\times$ lever $\times$ genotype interaction: $\left.F_{(13,637)}=3.75, p<0.0001\right)$, while only overall lever pressing, regardless of status, varied by sex (sex $\times$ genotype interaction: $\left.F_{(1,49)}=12.16, p=0.001\right)$, suggesting discriminative lever pressing does not vary by sex. Therefore, we excluded sex as a factor and found that similarly to cocaine intake, mutants pressed the active lever more than WT mice (session $\times$ genotype interaction: active lever pressing $F_{(13,663)}=3.48, p<0.0001$; Fig. $4 C$ ). On the other hand, inactive lever pressing was only slightly increased in Npas2 mutants compared to WT mice (trending main effect of genotype: inactive lever pressing $F_{(1,51)}=3.84, p=0.06$ ). Importantly, Npas 2 mutants showed similarly significant discrimination between the active and inactive lever (session $\times$ lever interaction: $\left.F_{(13,468)}=35.02, p<0.0001\right)$ as WT mice $($ session $\times$ lever interaction: $\left.F_{(13,858)}=66.81, p<0.0001\right)$.

During the dark phase, a four-way interaction further emphasizes that Npas 2 mutation differentially affects males
ZT14

and females (session $\times$ lever $\times$ sex $\times$ genotype interaction: $F_{(13,559)}=2.59$, $p=0.002)$. Specifically, female mutants pressed the active lever more than WT mice (session $\times$ genotype interaction: active lever pressing $F_{(13,260)}=2.40, p=0.0046$; Fig. $\left.4 D\right)$, while male mutants show no differences (Fig. 4E). Although inactive lever pressing is also changed in Npas 2 mutants females when compared to WT mice (session $\times$ genotype interaction: inactive lever pressing $F_{(13,260)}$ $=8.87, p<0.0001)$, responding is only increased on the first day of training, suggesting this increase is caused by perseveration on the inactive lever, which was previously reinforced with food, and not hyperactivity. As with the light phase, all mice discriminated between the active and inactive levers [session $\times$ lever interaction: WT mice $\left(F_{(13,338)}=22.4, p<0.0001\right)$, Npas 2 mutants $\left.\left(F_{(13,260)}=20.37, p<0.0001\right)\right]$.

To further explore the effect of Npas 2 mutation on reward, we measured CPP and locomotor sensitization. We previously found that Npas2 mutant mice have reduced CPP compared to WT (Ozburn et al., 2015), but only males were tested. Here, we conditioned male and female mice to 2.5 or $5 \mathrm{mg} / \mathrm{kg}$ cocaine and found that sex plays a pivotal role in CPP [sex $\times$ genotype interaction: $2.5 \mathrm{mg} / \mathrm{kg}\left(F_{(1,58)}=4.4, p=0.04\right)$, $\left.5 \mathrm{mg} / \mathrm{kg} \quad\left(F_{(1,57)}=7.01, p=0.01\right)\right]$. Although, we were able to replicate our previous finding that cocaine preference is reduced in male Npas2 mutants compared to WT controls (Ozburn et al., 2015), we interestingly found that female mutants showed no change in preference (Fig. 5A). We then confirmed that the lack of change in preference in mutant females is not because of TOD differences by measuring cocaine CPP during the dark phase. Again, cocaine preference was still unchanged in female Npas2 mutants (Fig. 5A).

During locomotor sensitization, we found that all mice sensitized to cocaine across sessions (main effect of session: $F_{(9,288)}=$ $136.43, p<0.001$ ), but the locomotor-activating effects of cocaine were dependent on sex and genotype (session $\times$ sex $\times$ genotype interaction: $\left.F_{(9,288)}=2.54, p=0.008\right)$. When analyzed independently, female Npas 2 mutant mice showed an increase in the locomotor activating effects of cocaine compared to controls (session $\times$ genotype interaction: $F_{(9,126)}=2.06, p=0.038$; Fig. $5 B$ ), while male mice showed a sensitization effect over multiple days (main effect of session: $F_{(9,162)}=99.76, p<0.001$; Fig. $5 C$ ). These results further support the critical role of sex in how NPAS2 regulates the behavioral effects of cocaine. Importantly, hyperactivity does not appear to contribute to the differences observed in Npas 2 mutants as locomotor activity is not increased in male or female Npas2 mutants following saline injections when compared to WT mice. These findings mirror our previous 
results demonstrating that locomotor response to novelty is not increased in male mutants (Ozburn et al., 2015).

Increased reinforcing and motivational properties of cocaine in Npas 2 mutant mice

Following acquisition, we measured the reinforcing properties of cocaine using a dose-response analysis. Throughout, Npas 2 mutant mice took more infusions compared to controls, indicating an overall increase in the efficacy of cocaine (dose $\times$ genotype interaction: $F_{(5,345)}=10.01, p$ $<0.0001$ ), which did not differ regardless of TOD or sex. Similar effects were seen during light phase (dose $\times$ genotype interaction: $F_{(5,180)}=3.98, p=0.002$; Fig. $6 C$ ) and dark phase self-administration (dose $\times$ genotype interaction: $F_{(5,165)}=7.51$, $p<0.001$; Fig. $6 F$ ). Next, a progressive ratio schedule was used to measure motivation (break point ratio), but a four-way ANOVA only revealed a main effect of genotype $\left(F_{(1,50)}=7.90, p=0.007\right)$. This was confirmed across TOD, where Npas 2 mutant mice worked harder for each infusion of cocaine than WT controls, as shown by a higher break point ratio during the light phase (main effect of genotype: $F_{(1,25)}=$ 4.92, $p=0.036$; Fig. $6 I$ ) and dark phase (main effect of genotype: $F_{(1,25)}=5.14$, $p=0.032$; Fig. 6I).

Increased extinction responding and cue-induced reinstatement in female Npas 2 mutant mice in the dark phase Mice then underwent extinction and cueinduced reinstatement to model relapselike drug seeking in the absence of cocaine. All mice extinguished responding (main effect of session: $F_{(9,432)}=28.68$, $p<0.0001$ ) and we found a trending four-factor interaction (session $\times$ sex $\times$ genotype $\times$ TOD interaction: $F_{(9,432)}=1.85, p$ $=0.058$ ) indicating divergent effects of genotype on males and females in the light and dark phase. We found a trend for Npas 2 mutation to increase extinction responding during the light phase (main effect of genotype: $F_{(1,23)}=3.06, p=0.09$; Fig. 7C), with small increases in responding in female (Fig. 7A) and male mutants (Fig. $7 B$ ). However, during the dark phase, a three-way interaction was found (session $\times$ sex $\times$ genotype interaction: $F_{(9,225)}=2.65, p=0.006$; Fig. $7 F$ ) indicating divergent effects of genotype on male and female mice. Specifically, female Npas 2 mutants showed an increase in early extinction responding in the dark phase (session $\times$ genotype interaction: $F_{(9,108)}=2.71$, $p=0.007$; Fig. $7 D$ ) compared to controls, while male mutants showed no differences (Fig. 7E).

After extinction, contingent, previously cocaine-associated cues were presented, which reinstated responding in all mice (main effect of lever: $F_{(1,48)}=53.38, p<0.0001$ ). Although no TOD differences were found in a four-way ANOVA, Npas 2 mutation differentially affected males and females (sex $\times$ genotype interaction: $F_{(1,485)}=4.49, p=0.039$. In subsequent analyses,
Npas2 mutation did not affect cue-induced reinstatement during the light phase $\left(F_{\mathrm{s}}<1\right)$ in female or male mice (Fig. $\left.7 G-I\right)$. Similar to extinction, drug seeking during reinstatement depended on sex and genotype during the dark phase (trending lever $\times$ sex $\times$ genotype interaction: $F_{(1,25)}=2.92, p=0.10$; Fig. $7 L$ ). Follow-up ANOVAs indicate that female Npas 2 mutants showed an increase in drug seeking (lever $\times$ genotype interaction: $F_{(1,12)}=4.58, p=0.05$; Fig. $\left.7 J\right)$ compared to WT mice, while male mutants showed no differences (Fig. $7 K$ ). Together, these findings indicate that in the absence of cocaine, initially or with cocaine-associated cues present, female Npas 2 mutants intensify their drug seeking, specifically in the dark phase.

\section{Circulating sex hormones contribute to increased cocaine self-administration in female Npas 2 mutant mice}

In order to determine whether ovarian hormones contribute to sex differences in self-administration in Npas 2 mutant mice, a separate cohort of females underwent an OVX or sham surgery before dark phase cocaine self-administration. As expected, we found that self-administration varied based on genotype and OVX (trending session $\times$ genotype $\times$ OVX interaction: $F_{(13,429)}=1.62$, $p=0.077)$. While sham mutant females showed moderately 

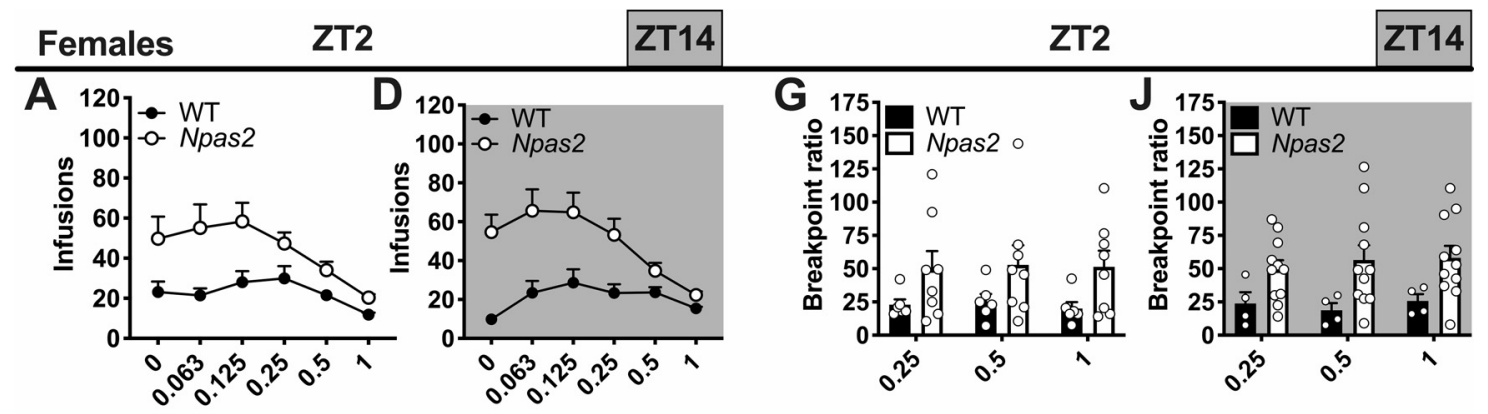

Males
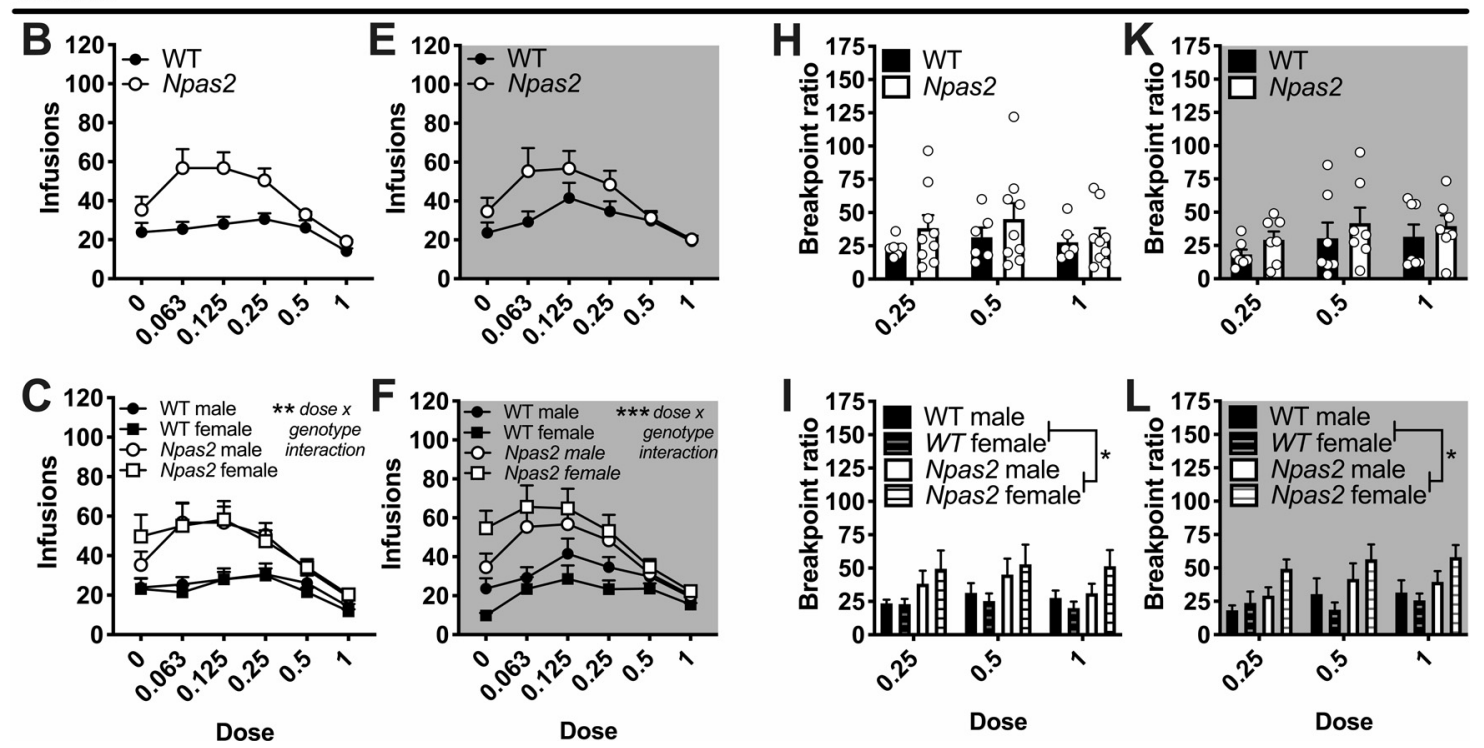

Figure 6. The reinforcing and motivational properties of cocaine were increased in Npas2 mutant mice. During a dose-response analysis (0-1 mg/kg/infusion) at ZT2 (light phase), Npas2 mutant mice self-administered more infusions of cocaine across dose in both $(\boldsymbol{A})$ female and $(\boldsymbol{B})$ male Npas2 mutant mice. $\boldsymbol{C}$, This significant increase in cocaine intake across sex suggests an increase in the reinforcing properties of cocaine. At ZT4, the reinforcing properties of cocaine were also increased in $(\boldsymbol{D})$ female and $(\boldsymbol{E})$ male mutant mice. Here, effects appear to be greater in female mutants, but $(\boldsymbol{F})$ no sex effect was found. During progressive ratio testing, $(\boldsymbol{G})$ female and $(\boldsymbol{H})$ male Npas2 mutant mice again worked harder for each infusion of cocaine. $\boldsymbol{I}$, Although a significant increase in breakpoint ratio was found across sex, this effect seems to be driven primarily by female mutant mice. Similar results are found during the dark phase, wherein break point ratio was increased in $(\boldsymbol{J})$ female and $(\boldsymbol{K})$ male Npas2 mutants. $\boldsymbol{L}$, Again, female mutants appear to be particularly affected, but no significant effect of sex was found. Mean $+S E M$; individual data points are shown in $\mathbf{G}-\mathbf{L}, * p<0.05, * * p<0.01, * * * p<0.001, n=4-11$.

increased cocaine self-administration compared to sham WT females (main effect of genotype: $F_{(1,18)}=4.09, p=0.058$; Fig. $8 A$ ), no effect was found in OVX WT and mutant mice $\left(F_{s}<1\right.$; Fig. $8 B)$. Furthermore, total drug intake was slightly increased in mutant sham compared to WT sham females $\left(t_{(18)}=1.63, p=0.059\right.$; Fig. $8 C)$, but not mutant OVX compared to WT OVX females $(t<1$; Fig. $8 D$ ). These findings suggest that sex hormones mediate the greater effects of Npas 2 mutation seen in female mice.

Increased $\Delta$ FosB expression in $\mathrm{D} 1+$ neurons in Npas 2 mutant females following dark phase cocaine selfadministration

In order to determine which striatal regions might mediate increased self-administration in Npas 2 mutant females, we measured cocaine-induced expression of $\Delta \mathrm{FosB}$, a stable, longlasting variant of FosB (Robison et al., 2013). Female mice selfadministered cocaine during the light or dark phase. Mice were limited to 25 infusions to normalize acquisition [main effect of genotype: light $\left(F_{(1,9)}=2.73, p=0.133\right)$, dark $(F<1)$; genotype $\times$ session interaction: light $(F<1)$, dark $\left(F_{(13,117)}=2.23, p=0.012\right.$, no significant post hocs $\left.)\right]$ between WT and Npas 2 mutant mice (Fig. 9A). Tissue was harvested 24 $\mathrm{h}$ after the last self-administration session.
We quantified the percentage of $\mathrm{D} 1+$ and D1- cells expressing $\triangle$ FosB in the NAc core, NAc shell, DLS, and DMS (Fig. 9B). No genotype differences were found in $\Delta$ FosB expression after light phase self-administration, but dark phase Npas 2 mutant females had slightly increased $\Delta$ FosB expression in the NAc shell (main effect of genotype: $F_{(1,9)}=4.16, p=$ 0.072) compare to WT females. In both the NAc core and DLS, this increase in $\Delta$ FosB was specific to D1+ cells [cell $\times$ genotype: NAc core $\left(F_{(1,8)}=3.97, p=0.082\right)$, DLS $\left(F_{(1,10)}=5.64, p=\right.$ $0.039)]$. No effects were seen in the DMS. Throughout, $\Delta$ FosB expression was higher in $\mathrm{D} 1+$ compared to D1- cells [main effect of cell-type: NAc $\left(F_{(1,18)}=30.47, p<0.0001\right)$, DS $\left(F_{(1,19)}\right.$ $=27.66, p<0.0001)$ ].

\section{Most DEGs in Npas2 mutant females are in the DLS and many are $\Delta$ FosB targets}

We next aimed to identify possible mechanisms that could be driving increased dark phase cocaine self-administration in female Npas 2 mutant mice. Since drug taking is increased early in self-administration (Fig. 2D), we believe predispositions exist in female mutants that drive this increase. Given regional differences in cocaine-induced striatal activation in female mutants, we identified DEGs in the NAc, DLS, and DMS of cocaine-naive 

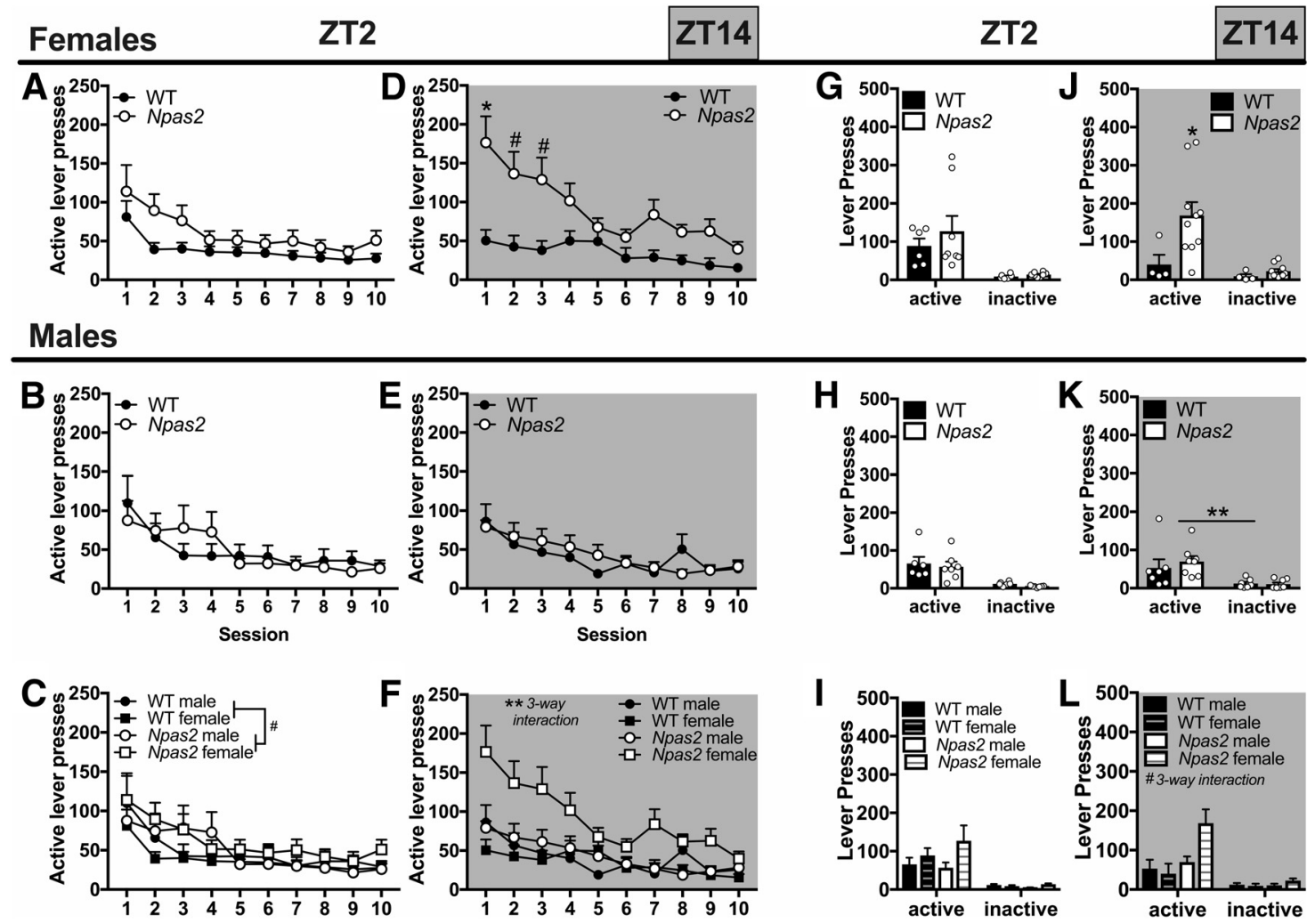

Figure 7. Increased extinction responding and cue-induced reinstatement in female Npas2 mutant mice during the dark phase. Following progressive ratio, responding on the cocaine-associated lever was extinguished over the course of at least $10 \mathrm{~d}$. Following extinction, responding on the active lever was reinstated with the presence of previously cocaine-associated cues. We found a very slight increase in extinction responding during the light phase in $(\boldsymbol{A})$ female and $(\boldsymbol{B})$ male mutant mice, as indicated by a $(\boldsymbol{C}$ trending effect of genotype. On the other hand, during the dark phase, extinction responding was only increased in $(\boldsymbol{D})$ female Npas2 mutants, while $(\boldsymbol{E})$ male mutants were unaffected. $\boldsymbol{F}$, This sex difference was confirmed by an interaction between session, sex, and mutation. A similar pattern was detected for cue-induced reinstatement, wherein $(\boldsymbol{G}-\boldsymbol{I})$ no effects were found during the light phase, but $(\boldsymbol{I})$ female and $(\boldsymbol{K})$ male mice were differentially affected by Npas2 mutation in the dark phase. $L$, A trending interaction was found and female Npas2 mutants responded significantly more during cue-induced reinstatement, suggesting increased drug seeking, but no differences were

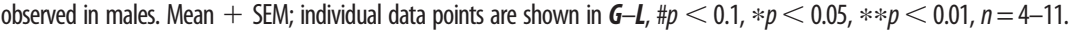

WT and Npas2 mutant females in the dark phase (Extended Data Figs. 9-1, 9-2, 9-3). Using cut-offs of $p<0.05$ (uncorrected) and fold change $(\mathrm{FC})>1.3$, we found 343 DEGs in the NAc, 362 in the DMS and 922 in the DLS (Fig. 9D). Because of the leniency of this $p$ value, some false positives are expected and fewer DEGs were found at more stringent cut-offs (Fig. 9D). Striatal regions that are similarly activated after self-administration in Npas2 mutants show parallel changes in gene expression. The NAc and DLS, where $\triangle$ FosB expression is increased in mutant $\mathrm{D} 1+$ neurons, show a high level of overlap in DEGs (Fig. 9E). However, the NAc and DLS show very little overlap with the DMS, where $\Delta$ FosB expression is not increased (Fig. $9 E-G$ ).

We used a ranked $p$ value meta-analysis (Huo et al., 2020) to identify DEGs specific to the DLS and NAc. Of the 463 DEGs (meta- $p<0.05$ ), many that are similarly regulated appear to modulate neurotransmission, which might contribute to increased self-administration seen here. These DEGs encode potassium channels (e.g., Kcn1l, Kcnc2, Kcna4, Kcna6, etc.), GABA receptor subunits (e.g., Gabrd, Gabra3, etc.), matrix metallopeptidases (Mmp14), as well as the small rho GTPase Rhoc and Snap23, which encodes machinery necessary for vesicular fusion. Potassium channels were one of the most significant DEG categories and were primarily upregulated in both the DLS and NAc of Npas2 mutant females.

Importantly, IPA revealed that highly significant DE pathways in Npas2 mutant females in the DLS include CREB1 targets, G-protein signaling and $\triangle$ FosB targets (Fig. 9I). This suggests that even at baseline, Npas 2 mutant females might have increased $\triangle F$ FosB and CREB-mediated transcription in the DLS, which is further exacerbated in D1+ cells by cocaine self-administration (Fig. 9B), but future experiments are needed to test this hypothesis directly.

As expected, the DEGs found across all three regions included mainly core circadian genes: Ciart, Arntl (Bmal1), Nr1d1, Cipc, Bhlhe 41, and Dbp. Arntl was the only upregulated circadian gene in Npas 2 mutant mice, likely to compensate for its inability to form a complex with the mutated Npas2. IPA also found significant enrichment in the pathway "circadian rhythms" across all regions, but especially the NAc (Fig. 9I-K). Fifteen other DEGs were identified in all three regions suggesting they might be important target genes of Npas2. These include protein kinases (Kitl, Camkk1) and genes that are protective against oxidative stress (Gpx6 and Hebp2). Fabp7 was the most upregulated gene in Npas 2 mutants and plays a role in fatty acid uptake, transport and metabolism in astrocytes (Chmurzyńska, 2006).

\section{Discussion}

Overall, Npas 2 mutation increases cocaine intake and the propensity to self-administer cocaine in a sex-dependent and circadian-dependent manner. In the light phase, cocaine taking, reinforcement and motivation are increased across sex. During the dark phase, females are more affected; reinforcement and motivation are increased across sex, while female mutants have increased drug taking, extinction responding and reinstatement. Females also appear to be driving effects on motivation, since 
A

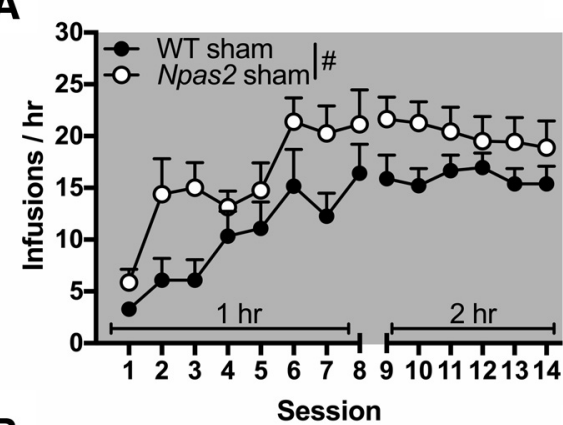

B

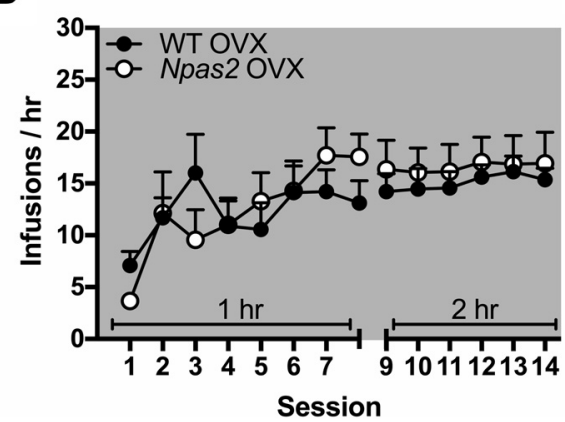

C

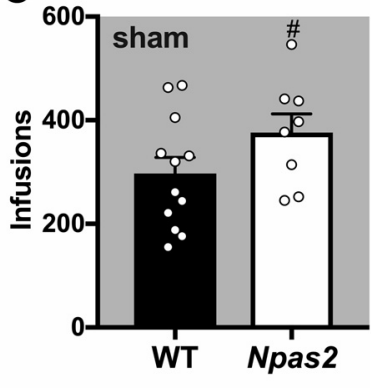

D

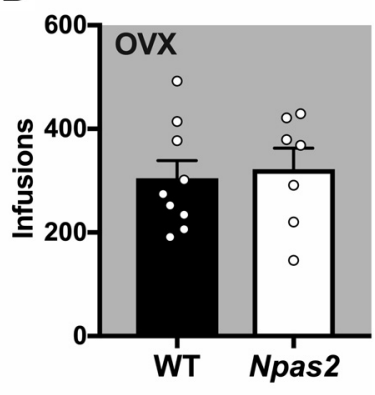

Figure 8. OVX reversed increased cocaine self-administration in Npas2 mutant females in the dark phase. A separate cohort of female mice underwent sham surgery or OVX before being trained to self-administer intravenous cocaine. $\boldsymbol{A}$, Sham surgery treated mice recapitulated our original finding that Npas2 mutant females take more cocaine than their WT counterparts during acquisition. $\boldsymbol{B}, 0$ n the other hand, OVX seemed to reverse this effect with no differences seen between mutant and WT mice. These results were confirmed by total drug intake (infusions), which are (C) moderately increased in sham-treated Npas2 mutant mice, but not (D) OVX mice. Mean + SEM; individual data points are shown in $\boldsymbol{C}$ and $\boldsymbol{D}$, $\# p<0.1, n=7-12$.

female mutants have the highest break point ratios during both TOD, although a sex difference was not found. Interestingly, while males show contradicting effects of Npas 2 mutation on light phase cocaine reward and self-administration, self-administration is uniquely affected in females. While it is not uncommon to find opposing results for these drug-related behaviors (Larson et al., 2011), detecting a selective change in volitional drug self-administration, as with females here, is more typical.

It is well known that sex differences exist in circadian rhythms and that circulating estradiol contributes to these differences (Varnäs et al., 2003; Krizo and Mintz, 2015). Sex differences are also frequently found in the rhythmicity of peripheral circadian genes (Lu et al., 2013) and the master pacemaker, the suprachiasmatic nucleus (SCN; Bailey and Silver, 2014). Although less is known about the extra-SCN brain, females show earlier peaks in circadian genes in the prefrontal cortex in humans (Lim et al., 2013), and the robustness of diurnal gene rhythms can vary by sex and brain region in rodents (Chun et al., 2015). These findings indicate that SCN-independent behaviors could also be affected by circulating hormones.

Despite an intersection between rhythms, hormones and extra-SCN behavior, research investigating how altered circadian rhythms, for example from circadian gene mutations, affect behavior sex dependently is limited. One key paper found that female Clock mutant mice show more robust increases in exploratory and escape-seeking behavior (Easton et al., 2003). Sex differences have been examined in Npas 2 mutants, but only in the context of sleep and locomotor activity. Importantly, Npas 2 mutation does not affect rhythms differently in males and females at baseline (Dudley et al., 2003), only under pathologic conditions, such as sleep deprivation (Franken et al., 2006),

suggesting our observed sex differences are not confounded by baseline differences. Since cocaine exposure disrupts circadian rhythms and sleep (Schierenbeck et al., 2008; Angarita et al., 2016), self-administration could be inducing sex-dependent sleep and rhythm disruptions, which might lead to sex differences in cocaine intake.

To determine whether circulating hormones might contribute to increased self-administration in Npas2 mutants, we ovariectomized female mice before dark phase cocaine selfadministration. Female OVX mice with nonfunctional NPAS2 showed no increase in self-administration, suggesting ovarian hormones could be driving enhanced effects in Npas2 mutant females. It is critical to continue examining how circadian genes affect behavior sex dependently, particularly in the context of SUD since its prevalence varies by sex (Kosten et al., 1993; Robbins et al., 1999; Kennedy et al., 2013). Interestingly, our sham controls only showed a trending increase $(p=0.58)$ in selfadministration, which is likely because of these mice being older or the stress of an additional surgery. These factors are crucial to consider when investigating sex differences in future studies.

In order to further identify how mutations in Npas 2 contribute to SU in females, we measured striatal activation using $\triangle$ FosB. While other Fos proteins are transiently induced by acute drug exposure, $\triangle F$ FosB is a stable, longlasting variant induced by long-term exposure (Robison et al., 2013). This allows activation from chronic drug self-administration to be measured. Here, female WT and Npas 2 mutant mice self-administered cocaine, but drug intake was limited to normalize increased cocaine exposure in mutant mice.

The striatum is primarily comprised of neuron populations expressing D1 or D2 dopamine receptors (Lu et al., 1998). Activation of D1-expressing neurons in the NAc promotes cocaine preference (Lobo et al., 2010) and cocaine activates D1 and D2 neurons differently (Bertran-Gonzalez et al., 2008), inducing $\Delta$ FosB in D1 neurons (Lobo et al., 2013). NPAS2 is highly enriched in the striatum (Garcia et al., 2000), specifically in D1 neurons (Ozburn et al., 2015) and we recently demonstrated that Npas 2 knock-down in the NAc increases glutamatergic excitability onto D1 cells (Parekh et al., 2019). Therefore, we measured $\Delta$ FosB expression in $\mathrm{D} 1+$ and $\mathrm{D} 1-$ cells throughout the striatum and found that $\triangle \mathrm{FosB}$ expression was increased in $\mathrm{D} 1+$ neurons in the NAc core and DLS of Npas 2 mutant females. The NAc shell was also moderately affected, in D1+ and D1- cells, but effects in the dorsal striatum were confined to the DLS. Since the DLS mediates habitual drug seeking, and the DMS goal-directed decision-making (Yin et al., 2004), Npas2 mutant females may rely more heavily on habitual decision-making strategies during self-administration. Future studies could use action-outcome contingency degradation or outcome devaluation to measure response strategies in Npas 2 mutant females.

Increased induction of $\Delta \mathrm{FosB}$ in Npas 2 mutants was also specific to the dark phase when the behavioral effects of Npas2 mutation are greatest. Npas 2 expression peaks in the NAc 

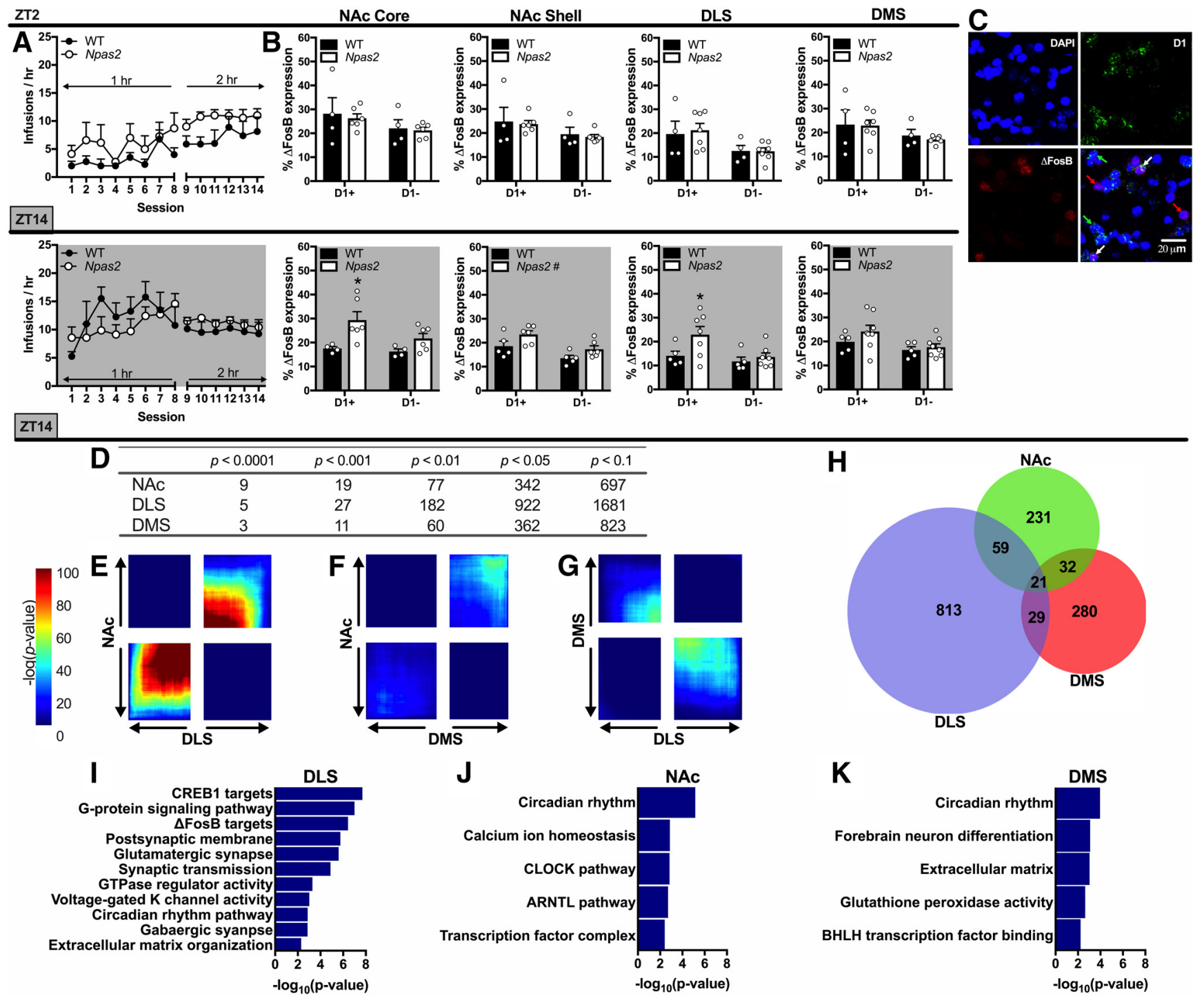

Figure 9. Striatal activation and differential gene expression in Npas2 mutant females in the dark phase. $A, A$ cohort of female mice were trained to self-administer cocaine during either the light phase or dark phase. Infusions were limited to 25 to normalize cocaine intake between groups. $\boldsymbol{B}$, No differences were found between genotypes in $\Delta$ Fos $B$ expression following light phase cocaine self-administration. However, following dark phase, self-administration $\triangle F$ FosB expression was increased in Npas2 mutant females in the NAc core, shell, and DLS. This expression was specific to D1+ cells in the NAc core and DLS. Throughout, cocaine-induced $\triangle$ FosB expression was greater in D1+ compared to D1- cells. C, Representative staining is shown with the nucleus (DAPI, blue), D1 (green), and $\triangle \mathrm{FosB}$ (red) shown individually and as a composite image with 20- $\mu \mathrm{m}$ scale bar shown. $\boldsymbol{D}$, Table showing the cumulative number of DE genes between Npas2 mutant and WT female mice in the dark phase with a FC cutoff of 1.3. Various significance cutoffs are shown for the NAc, DLS, and DMS. E-G, RRHO plots showing various levels of overlap between genes that are changed with Npas2 mutation in the NAc, DLS, and DMS. $\boldsymbol{E}$, There is a high level of overlap between genes that are changed in the NAc and DLS, while $(\boldsymbol{F})$ very few genes are changed in both the NAc and DMS of Npas2 mutants. $\boldsymbol{G}$, Genes in the DMS and DLS are changed in opposite directions in Npas2 mutant females. $\boldsymbol{H}$, Venn diagram showing unique or overlapping DEGs in the NAC, DLS, and DMS with a cutoff of $p<0.05$ and FC $=1.3$. I-K, Highly significant pathways altered in Npas2 mutant females in the DLS, NAC, and DMS are shown. Extended Data list DEGs in the NAc (Extended Data Fig. 9-1), DLS (Extended Data Fig. 9-2), and DMS (Extended Data Fig. 9-3). Mean + SEM; individual data points are shown in $\boldsymbol{B}$, $\# p<0.1, * p<0.05, n=4-8$.

around ZT16 (Falcon et al., 2013) when dark phase self-administration was conducted. It stands to reason that mutating Npas2 would have a greater impact on behavior when mRNA expression is elevated. Higher expression suggests a functional necessity for NPAS2; however, a parallel protein rhythm has not been confirmed. Furthermore, drug intake in mice is typically higher during the dark phase, therefore, individuals could be more vulnerable to insults during periods predisposed to drug seeking. This TOD vulnerability emphasizes the importance of considering rhythms in gene expression in future studies.

In order to characterize the striatal mechanisms underlying increased dark phase self-administration in female Npas2 mutant mice, we identified DEGs in the NAc, DLS, and DMS in cocaine- naive mice. The NAc core and shell were pooled since cocaineinduced activation was increased in the core and, to a lesser extent, shell of mutants. As expected, we found overall changes in circadian rhythm-related genes; for example, Arntl was upregulated, likely to compensate for its inability to form a transcriptional complex with the mutated Npas2. Fabp7 was the most highly upregulated DEG in Npas2 mutants across all regions. It regulates fatty acid uptake in astrocytes, sleep (Gerstner et al., 2017) and drug seeking under stressful conditions (Hamilton et al., 2018). Fabp7 is rhythmically expressed throughout the brain (Schnell et al., 2014) and is similarly upregulated in Arntl and Nr1d1 knock-out mice (Schnell et al., 2014; Gerstner and Paschos, 2020). Fabp7 could be upregulated in Npas2 mutants 
because of the downregulation of Nr1d1, which represses Fabp7 (Schnell et al., 2014).

Although some DEGs were changed throughout the striatum, patterns typically varied by subregion. The DLS and NAc had the most similar pattern of DE, while the DLS/DMS and DMS/ NAc had less overlap. Less significant DE was also found in the DMS (Extended Data Fig. 9-3). These findings parallel cocaineinduced activation patterns and emphasize how the DMS is differentially affected by Npas 2 mutation.

We next identified target genes in Npas 2 mutant females that might predispose increased cocaine self-administration. Using a meta-analysis (Huo et al., 2020), we identified 463 DEGs specific to the DLS and NAc where cocaine-induced activation is found in Npas 2 mutants. Many of these similarly regulated DEGs modulate neurotransmission and could therefore mediate increased glutamatergic transmission in the NAc of Npas 2 knock-down mice (Parekh et al., 2019), which could contribute to increased self-administration. These DEGs encode GABA receptor subunits, matrix metallopeptidases, small rho GTPases and synaptosomal proteins. GABAergic transmission is a promising target, since NPAS2 directly binds GABA receptor subunits (Ozburn et al., 2017). One of the most common DEG categories was potassium channels, which were frequently upregulated and could be modulating action potential generation and short-term plasticity in the DLS and NAc of mutant females. Importantly, DEGs from the NAc could have been diluted since the shell was activated to a lesser extent than the core. Overall, the DLS is most impacted by Npas 2 mutation with additional DEGs identified that regulate neurotransmission: other GTPase-related genes (Arhgap9, Rasal1), scaffolding genes (Shank1), and glutamate receptor subunits (Gria4).

Interestingly, enriched pathways in the NAc, DMS and DLS are also distinct. Circadian pathways were unsurprisingly identified in all regions (Dong et al., 2011; Baranger et al., 2016), since disruptions in circadian rhythms and transcription contribute to SU vulnerability. Importantly, circadian transcription factor (CLOCK, ARNTL) pathways were particularly significant in the NAc, suggesting a critical role in linking rhythm disruptions and drug use. Meanwhile, top pathways in the DLS suggest an increase in $\triangle F$ FosB and CREB signaling at baseline, which could be exacerbated following self-administration. Other DLS pathways correspond to unique DEGs that mediate neurotransmission and synaptic plasticity. Future studies could examine the role of these genes in increased self-administration in Npas2 mutants. For example, reducing $\Delta$ FosB-mediated transcription in Npas 2 mutants in D1+ cells in the DLS might normalize cocaine self-administration.

Ultimately, these results demonstrate that decreased function in NPAS2 drives vulnerability for SU in a circadian-dependent and sex-dependent manner. Parallel changes in striatal activation and gene expression in Npas 2 mutant females in the dark phase suggest that gene expression changes, perhaps mediated by $\triangle$ FosB signaling, underlie behavioral vulnerabilities associated with mutating the key circadian transcription factor Npas2.

\section{References}

Abarca C, Albrecht U, Spanagel R (2002) Cocaine sensitization and reward are under the influence of circadian genes and rhythm. Proc Natl Acad Sci USA 99:9026-9030.

Angarita GA, Emadi N, Hodges S, Morgan PT (2016) Sleep abnormalities associated with alcohol, cannabis, cocaine, and opiate use: a comprehensive review. Addict Sci Clin Pract 11:9.
Bailey M, Silver R (2014) Sex differences in circadian timing systems: implications for disease. Front Neuroendocrinol 35:111-139.

Baird TJ, Gauvin DV (2000) Characterization of cocaine self-administration and pharmacokinetics as a function of time of day in the rat. Pharmacol Biochem.Behav 65:289-299.

Baranger DAA, Ifrah C, Prather AA, Carey CE, Corral-Frías NS, Drabant Conley E, Hariri AR, Bogdan R (2016) PER1 rs3027172 genotype interacts with early life stress to predict problematic alcohol use, but not reward-related ventral striatum activity. Front. Psychol 7:464.

Becker JB, Hu M (2008) Sex differences in drug abuse. Front Neuroendocrinol 29:36-47.

Bertran-Gonzalez J, Bosch C, Maroteaux M, Matamales M, Hervé D, Valjent E, Girault J-A (2008) Opposing patterns of signaling activation in dopamine D1 and D2 receptor-expressing striatal neurons in response to cocaine and haloperidol. J Neurosci 28:5671-5685.

Bi J, Gelernter J, Sun J, Kranzler HR (2014) Comparing the utility of homogeneous subtypes of cocaine use and related behaviors with DSM-IV cocaine dependence as traits for genetic association analysis. Am J Med Genet B Neuropsychiatr Genet 165:148-156.

Blomeyer D, Buchmann AF, Lascorz J, Zimmermann US, Esser G, Desrivieres S, Schmidt MH, Banaschewski T, Schumann G, Laucht M (2013) Association of PER2 genotype and stressful life events with alcohol drinking in young adults. PLoS One 8:e59136.

Cahill KM, Huo Z, Tseng GC, Logan RW, Seney ML (2018) Improved identification of concordant and discordant gene expression signatures using an updated rank-rank hypergeometric overlap approach. Sci Rep 8:9588.

Chmurzyńska A (2006) The multigene family of fatty acid-binding proteins (FABPs): function, structure and polymorphism. J Appl Genet 47:39-48.

Chun LE, Woodruff ER, Morton S, Hinds LR, Spencer RL (2015) Variations in phase and amplitude of rhythmic clock gene expression across prefrontal cortex, hippocampus, amygdala, and hypothalamic paraventricular and suprachiasmatic nuclei of male and female rats. J Biol Rhythms 30:417-436.

DePoy LM, McClung CA, Logan RW (2017a) Neural mechanisms of circadian regulation of natural and drug reward. Neural Plast 2017:5720842.

DePoy LM, Zimmermann KS, Marvar PJ, Gourley SL (2017b) Induction and blockade of adolescent cocaine-induced habits. Biol Psychiatry 81:595-605.

Dong L, Bilbao A, Laucht M, Henriksson R, Yakovleva T, Ridinger M, Desrivieres S, Clarke TK, Lourdusamy A, Smolka MN, Cichon S, Blomeyer D, Treutlein J, Perreau-Lenz S, Witt S, Leonardi-Essmann F, Wodarz N, Zill P, Soyka M, Albrecht U, et al. (2011) Effects of the circadian rhythm gene period 1 (Per1) on psychosocial stress-induced alcohol drinking. Am J Psychiatry 168:1090-1098.

Dudley CA, Erbel-Sieler C, Estill SJ, Reick M, Franken P, Pitts S, McKnight SL (2003) Altered patterns of sleep and behavioral adaptability in NPAS2-deficient mice. Science 301:379-383.

Easton A, Arbuzova J, Turek FW (2003) The circadian Clock mutation increases exploratory activity and escape-seeking behavior. Genes Brain Behav 2:11-19.

Falcon E, Ozburn A, Mukherjee S, Roybal K, McClung CA (2013) Differential regulation of the period genes in striatal regions following cocaine exposure. PLoS One 8:e66438.

Forbes EE, Dahl RE, Almeida JRC, Ferrell RE, Nimgaonkar VL, Mansour H, Sciarrillo SR, Holm SM, Rodriguez EE, Phillips ML (2012) PER2 rs2304672 polymorphism moderates circadian-relevant reward circuitry activity in adolescents. Biol Psychiatry 71:451-457.

Franken P, Dudley CA, Estill SJ, Barakat M, Thomason R, O'Hara BF, McKnight SL (2006) NPAS2 as a transcriptional regulator of non-rapid eye movement sleep: genotype and sex interactions. Proc Natl Acad Sci USA 103:7118-7123.

Gamsby JJ, Templeton EL, Bonvini LA, Wang W, Loros JJ, Dunlap JC, Green AI, Gulick D (2013) The circadian Per1 and Per2 genes influence alcohol intake, reinforcement, and blood alcohol levels. Behav Brain Res 249:1521.

Garcia JA, Zhang D, Estill SJ, Michnoff C, Rutter J, Reick M, Scott K, DiazArrastia R, McKnight SL (2000) Impaired cued and contextual memory in NPAS2-deficient mice. Science 288:2226-2230.

Gerstner JR, Paschos GK (2020) Circadian expression of Fabp7 mRNA is disrupted in Bmall KO mice. Mol Brain 13:26.

Gerstner JR, Perron IJ, Riedy SM, Yoshikawa T, Kadotani H, Owada Y, Van Dongen HPA, Galante RJ, Dickinson K, Yin JCP, Pack AI, Frank MG 
(2017) Normal sleep requires the astrocyte brain-type fatty acid binding protein FABP7. Sci Adv 3:e1602663.

Hamilton J, Marion M, Figueiredo A, Clavin BH, Deutsch D, Kaczocha M, Haj-Dahmane S, Thanos PK (2018) Fatty acid binding protein deletion prevents stress-induced preference for cocaine and dampens stressinduced corticosterone levels. Synapse 72:e22031.

Hatcher KM, SE R, Mahoney MM (2020) Modulation of circadian rhythms through estrogen receptor signaling. Eur J Neurosci 51:217-228.

Heger S, Seney M, Bless E, Schwarting GA, Bilger M, Mungenast A, Ojeda SR, Tobet SA (2003) Overexpression of glutamic acid decarboxylase-67 (GAD-67) in gonadotropin-releasing hormone neurons disrupts migratory fate and female reproductive function in mice. Endocrinology 144:2566-2579.

Huo Z, Tang S, Park Y, Tseng G (2020) P-value evaluation, variability index and biomarker categorization for adaptively weighted Fisher's meta-analysis method in omics applications. Bioinformatics 36:524-532.

Kennedy AP, Epstein DH, Phillips KA, Preston KL (2013) Sex differences in cocaine/heroin users: drug-use triggers and craving in daily life. Drug Alcohol Depend 132:29-37.

Ko CH, Takahashi JS (2006) Molecular components of the mammalian circadian clock. Hum Mol Genet 15:R271-R277.

Kosten TA, Gawin FH, Kosten TR, Rounsaville BJ (1993) Gender differences in cocaine use and treatment response. J Subst Abuse Treat 10:63-66.

Kowatch RA, Schnoll SS, Knisely JS, Green D, Elswick RK (1992) Electroencephalographic sleep and mood during cocaine withdrawal. J Addict Dis 11:21-45.

Krizo JA, Mintz EM (2015) Sex differences in behavioral circadian rhythms in laboratory rodents. Front Endocrinol (Lausanne) 5:234.

Larson EB, Graham DL, Arzaga RR, Buzin N, Webb J, Green TA, Bass CE, Neve RL, Terwilliger EF, Nestler EJ, Self DW (2011) Overexpression of CREB in the nucleus accumbens shell increases cocaine reinforcement in self-administering rats. J Neurosci 31:16447-16457.

Li J, Tseng GC (2011) An adaptively weighted statistic for detecting differential gene expression when combining multiple transcriptomic studies. Ann Appl Stat 5:994-1019.

Lim ASP, Myers AJ, Yu L, Buchman AS, Duffy JF, De Jager PL, Bennett DA (2013) Sex difference in daily rhythms of clock gene expression in the aged human cerebral cortex. J Biol Rhythms 28:117-129.

Lobo MK, Covington HE, Chaudhury D, Friedman AK, Sun H, DamezWerno D, Dietz DM, Zaman S, Koo JW, Kennedy PJ, Mouzon E, Mogri M, Neve RL, Deisseroth K, Han MH, Nestler EJ (2010) Cell type-specific loss of BDNF signaling mimics optogenetic control of cocaine reward. Science 330:385-390.

Lobo MK, Zaman S, Damez-Werno DM, Koo JW, Bagot RC, DiNieri JA, Nugent A, Finkel E, Chaudhury D, Chandra R, Riberio E, Rabkin J, Mouzon E, Cachope R, Cheer JF, Han MH, Dietz DM, Self DW, Hurd $\mathrm{YL}$, Vialou $\mathrm{V}$, et al. (2013) $\Delta$ FosB induction in striatal medium spiny neuron subtypes in response to chronic pharmacological, emotional, and optogenetic stimuli. J Neurosci 33:18381-18395.

Logan RW, Williams WP, McClung CA (2014) Circadian rhythms and addiction: mechanistic insights and future directions. Behav Neurosci 128:387-412.

Lu XY, Ghasemzadeh MB, Kalivas PW (1998) Expression of D1 receptor, D2 receptor, substance $\mathrm{P}$ and enkephalin messenger RNAs in the neurons projecting from the nucleus accumbens. Neuroscience 82:767-780.

Lu YF, Jin T, Xu Y, Zhang D, Wu Q, Zhang YKJ, Liu J (2013) Sex differences in the circadian variation of cytochrome $\mathrm{P} 450$ genes and corresponding nuclear receptors in mouse liver. Chronobiol Int 30:1135-1143.

Matuskey D, Pittman B, Forselius E, Malison RT, Morgan PT (2011) A multistudy analysis of the effects of early cocaine abstinence on sleep. Drug Alcohol Depend 115:62-66.

McClung CA (2007) Circadian genes, rhythms and the biology of mood disorders. Pharmacol Ther 114:222-232.

McClung CA, Sidiropoulou K, Vitaterna M, Takahashi JS, White FJ, Cooper DC, Nestler EJ (2005) Regulation of dopaminergic transmission and cocaine reward by the clock gene. Proc Natl Acad Sci USA 102:9377-9381.

Morgan PT, Malison RT (2007) Cocaine and sleep: early abstinence. ScientificWorldJournal 7:223-230.
Ozburn AR, Larson EB, Self DW, McClung CA (2012) Cocaine self-administration behaviors in Clock $\Delta 19$ mice. Psychopharmacology (Berl) 223:169-177.

Ozburn AR, Falcon E, Mukherjee S, Gillman A, Arey R, Spencer S, McClung CA (2013) The role of clock in ethanol-related behaviors. Neuropsychopharmacology 38:2393-2400.

Ozburn AR, Falcon E, Twaddle A, Nugent AL, Gillman AG, Spencer SM, Arey RN, Mukherjee S, Lyons-Weiler J, Self DW, McClung CA (2015) Direct regulation of diurnal Drd3 expression and cocaine reward by NPAS2. Biol Psychiatry 77:425-433. Elsevier.

Ozburn AR, Kern J, Parekh PK, Logan RW, Liu Z, Falcon E, Becker-Krail D, Purohit K, Edgar NM, Huang Y, McClung CA (2017) NPAS2 regulation of anxiety-like behavior and GABAA receptors. Front Mol Neurosci 10:360.

Parekh PK, Logan RW, Ketchesin KD, Becker-Krail D, Shelton MA, Hildebrand MA, Barko K, Huang YH, McClung CA (2019) Cell-type specific regulation of nucleus accumbens synaptic plasticity and cocaine reward sensitivity by the circadian protein, NPAS2. J Neurosci 39:46574667.

Perrotti LI, Weaver RR, Robison B, Renthal W, Maze I, Yazdani S, Elmore RG, Knapp DJ, Selley DE, Martin BR, Sim-Selley L, Bachtell RK, Self DW, Nestler EJ (2008) Distinct patterns of DeltaFosB induction in brain by drugs of abuse. Synapse 62:358-369.

Reppert SM, Weaver DR (2002) Coordination of circadian timing in mammals. Nature 418:935-941.

Robbins SJ, Ehrman RN, Childress AR, O’Brien CP (1999) Comparing levels of cocaine cue reactivity in male and female outpatients. Drug Alcohol Depend 53:223-230.

Roberts DCS, Brebner K, Vincler M, Lynch WJ (2002) Patterns of cocaine self-administration in rats produced by various access conditions under a discrete trials procedure. Drug Alcohol Depend 67:291-299.

Robison AJ, Vialou V, Mazei-Robison M, Feng J, Kourrich S, Collins M, Wee S, Koob G, Turecki G, Neve R, Thomas M, Nestler EJ (2013) Behavioral and structural responses to chronic cocaine require a feedforward loop involving $\Delta$ FosB and calcium/calmodulin-dependent protein kinase II in the nucleus accumbens shell. J Neurosci 33:4295-4307.

Schierenbeck T, Riemann D, Berger M, Hornyak M (2008) Effect of illicit recreational drugs upon sleep: cocaine, ecstasy and marijuana. Sleep Med Rev 12:381-389.

Schnell A, Chappuis S, Schmutz I, Brai E, Ripperger JA, Schaad O, Welzl H, Descombes P, Alberi L, Albrecht U (2014) The nuclear receptor REV$\mathrm{ERB} \alpha$ regulates Fabp7 and modulates adult hippocampal neurogenesis. PLoS One 9:e99883.

Sleipness EP, Sorg BA, Jansen HT (2005) Time of day alters long-term sensitization to cocaine in rats. Brain Res 1065:132-137.

Smith RJ, Lobo MK, Spencer S, Kalivas PW (2013) Cocaine-induced adaptations in D1 and D2 accumbens projection neurons (a dichotomy not necessarily synonymous with direct and indirect pathways). Curr Opin Neurobiol 23:546-552.

Spanagel R, Rosenwasser AM, Schumann G, Sarkar DK (2005) Alcohol consumption and the body's biological clock. Alcohol Clin Exp Res 29:15501557.

Takahashi JS (2017) Transcriptional architecture of the mammalian circadian clock. Nat Rev Genet 18:164-179.

Varnäs K, Halldin C, Pike VW, Hall H (2003) Distribution of 5-HT4 receptors in the postmortem human brain-an autoradiographic study using [125I]SB 207710. Eur Neuropsychopharmacol 13:228-234.

Wise RA, Rompre PP (1989) Brain dopamine and reward. Annu Rev Psychol 40:191-225.

Yawata S, Yamaguchi T, Danjo T, Hikida T, Nakanishi S (2012) Pathwayspecific control of reward learning and its flexibility via selective dopamine receptors in the nucleus accumbens. Proc Natl Acad Sci USA 109:12764-12769.

Yin HH, Knowlton BJ, Balleine BW (2004) Lesions of dorsolateral striatum preserve outcome expectancy but disrupt habit formation in instrumental learning. Eur J Neurosci 19:181-189. 